
Environmental Health

\title{
Occurrence, Distribution, and Concentrations of Selected Contaminants in Streambed- and Suspended-Sediment Samples Collected in Bexar County, Texas, 2007-09
}

\section{Key Findings}

- The U.S. Geological Survey collected streambed- and suspended-sediment samples during 2007-09 from 20 sites in 8 watersheds in Texas: Medio Creek, Medina River, Elm Creek, Martinez Creek, Chupaderas Creek, Leon Creek, Salado Creek, and San Antonio River (fig.1). The samples were analyzed for major and trace elements, pesticides, polychlorinated biphenyls (PCBs), and polycyclic aromatic hydrocarbons (PAHs).
- The most frequently detected organic chemicals were the chlordane pesticides. The samples from Leon Creek and San Antonio River had more detections of all contaminants than other watersheds.

- Concentrations of cadmium, chromium, and DDE in the samples collected from the Leon Lackland, Leon Quintana, and Leon 35 sites were above their probable effect concentrations, indicating harmful effects are likely on organisms living in the sediments at those sites.
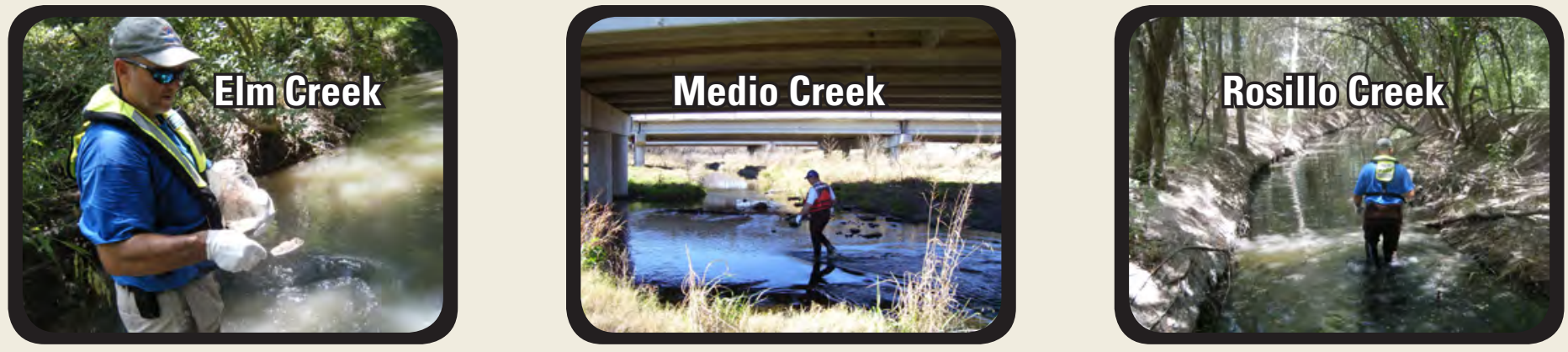

\section{What Are Some of the Chemicals in the Sediments?}

\section{Cadmium}

A naturally occuring trace element used in batteries, pigments, metal coatings, and plastics.

\section{Chromium}

A naturally occurring trace element used as an alloy in metals (predominantly steel) and in chrome plating.

Lead

A naturally occurring trace element used in gasoline until the 1970s and currently used in batteries, ammunition, metal products, and radiation shields.

Zinc

A naturally occurring element used for coatings, batteries, and metal alloys.

\section{Chlordane}

A synthetic pesticide used between 1948 and 1983 on corn and citrus crops and home lawns and gardens; its use continued until 1988 to control termites.

\section{DDT, DDE, and DDD}

Dichlorodiphenyltrichloroethane (DDT) is a synthetic pesticide used between 1939 and 1972 to control insects on crops and disease-carrying insects such as mosquitoes with malaria. Dichlorodiphenyldichloroethylene (DDE) and dichlorodiphenyldichloroethane (DDD) are breakdown products of DDT and have similar chemical and physical properties to DDT.
PCBs

Polychlorinated biphenyls (PCBs) are mixtures of organic compounds manufactured between the 1930s and 1977 and used as plasticizers, lubricants, and coolants. Total PCB is the sum of 18 individual PCB compounds.

PAHs

Polycyclic aromatic hydrocarbons (PAHs) are a group of organic compounds that form during the burning of carbon-based substances such as wood, gasoline, or meat. PAHs also are in tires, coal tar, crude oil, medicines, plastics, and pesticides. Total PAH is the sum of the most commonly reported individual PAH compounds. 


\section{Background}

High concentrations of sediment-associated contaminants are typically associated with urban areas such as San Antonio, Texas, in Bexar County, the seventh most populous city in the United States (U.S. Census Bureau, 2009). U.S. Geological Survey personnel periodically collected surficial streambed-sediment samples during 2007-09 and collected suspended-sediment samples from selected streams after storms during 2008 and 2009. All sediment samples were analyzed for major and trace elements, pesticides, polychlorinated biphenyls (PCBs), and polycyclic aromatic hydrocarbons (PAHs).

\section{Two Methods of Sediment Sampling}

When possible, streambed-sediment sampling met the following criteria: sites were at or near previously sampled sites and USGS streamflow-gaging stations, in areas that were accessible by wading, and in the upper and lower parts of each watershed.

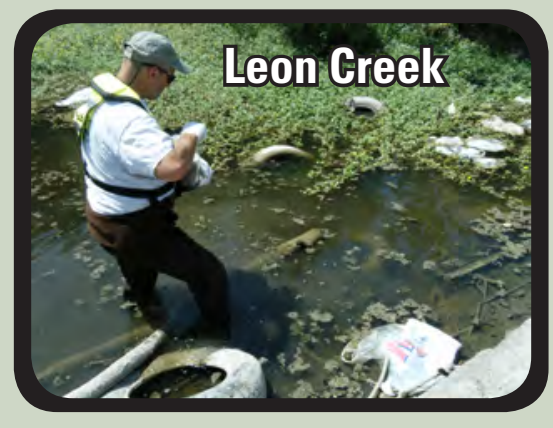

Streambed-sediment samples were combined from multiple depositional zones within a single stream reach at each site. The sediments were scooped into a glass bowl, mixed, and then sieved to a standard grain size.
Suspended-sediment sampling sites were located at the downstream-most sites in most of the watersheds in the study area.

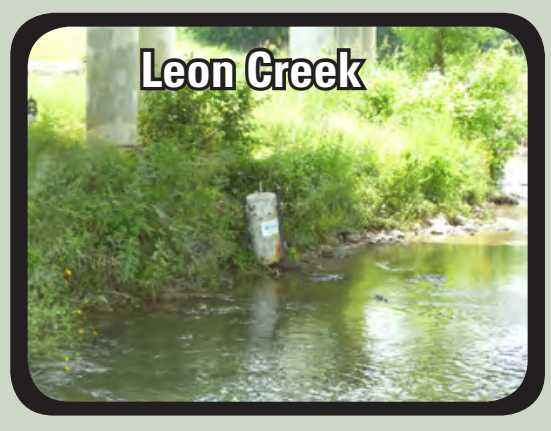

Suspended-sediment samples were collected with passive samplers (25-liter bottle inside a steel cylinder) installed near the stream channels. The bottle inside the passive sampler filled when it rained and streamflow rose. Suspended-sediment samples were isolated from the stormwater through filtration.

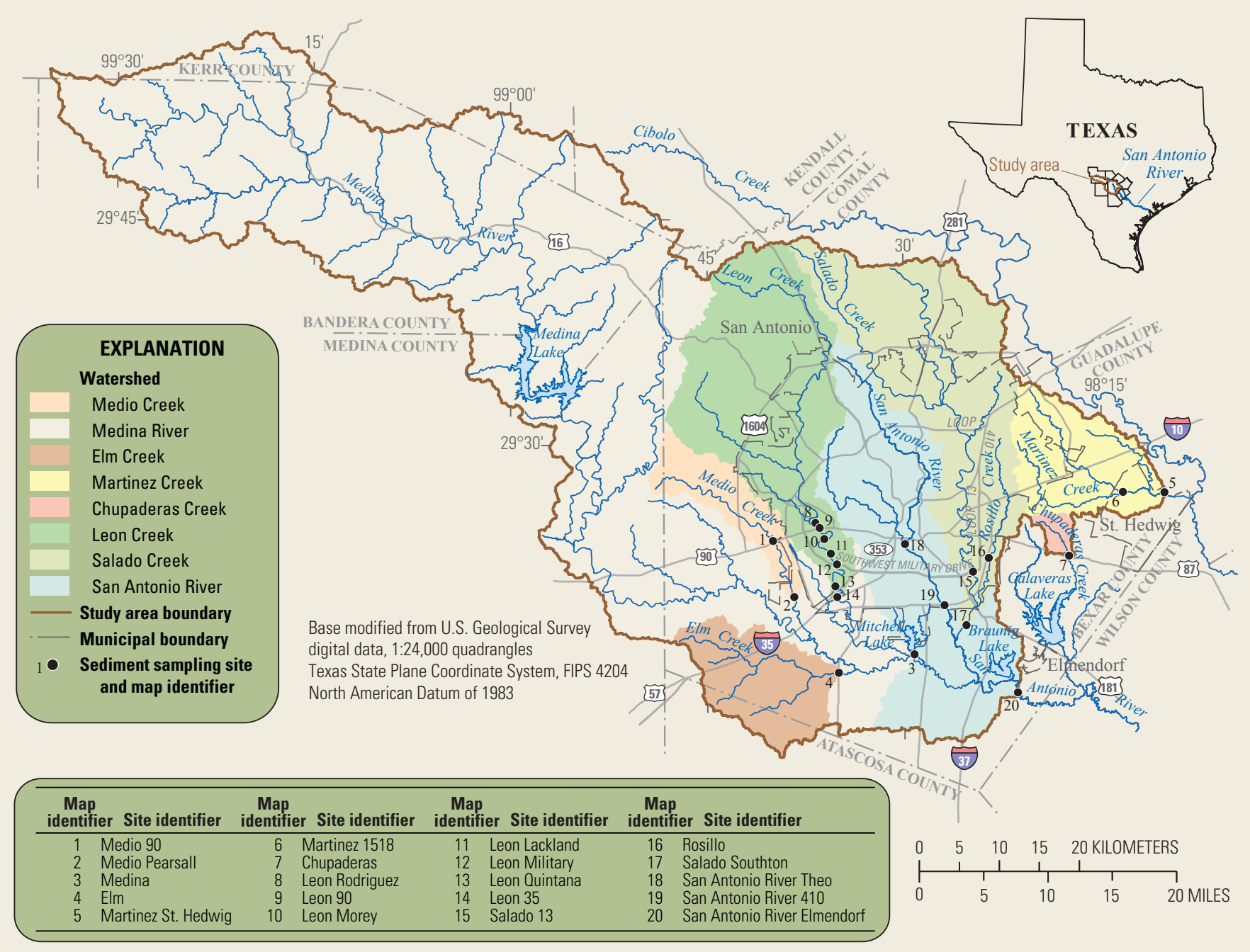

Figure 1. Locations of streambed-sediment and suspended-sediment sampling sites in Bexar County, Texas, 2007-09. 


\section{How Often Were These Chemicals Found?}

All of the trace elements discussed in this fact sheet occur naturally and were found in all of the sediment samples; however, the pesticides, PCBs, and most PAHs are associated with human activities and were not found in all of the sediment samples, particularly those samples collected in the watersheds with low human populations (Medina River, Elm Creek, and Chupaderas Creek). The number of times pesticides, PCBs, and PAHs were found varied widely by watershed (fig. 2).
- Chlordane pesticides were found most often, occurring in 94 percent of the samples and in every watershed.

- DDT pesticides were found in 22 percent of the samples. No DDT pesticides were found in the samples collected from Medina River, Elm Creek, or Chupaderas Creek; they were found most often in the samples collected from Leon Creek and San Antonio River.

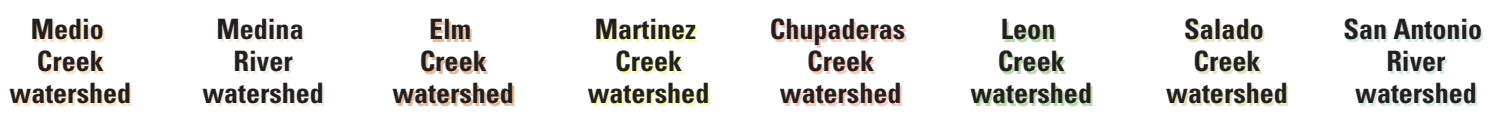

Detections, in percent

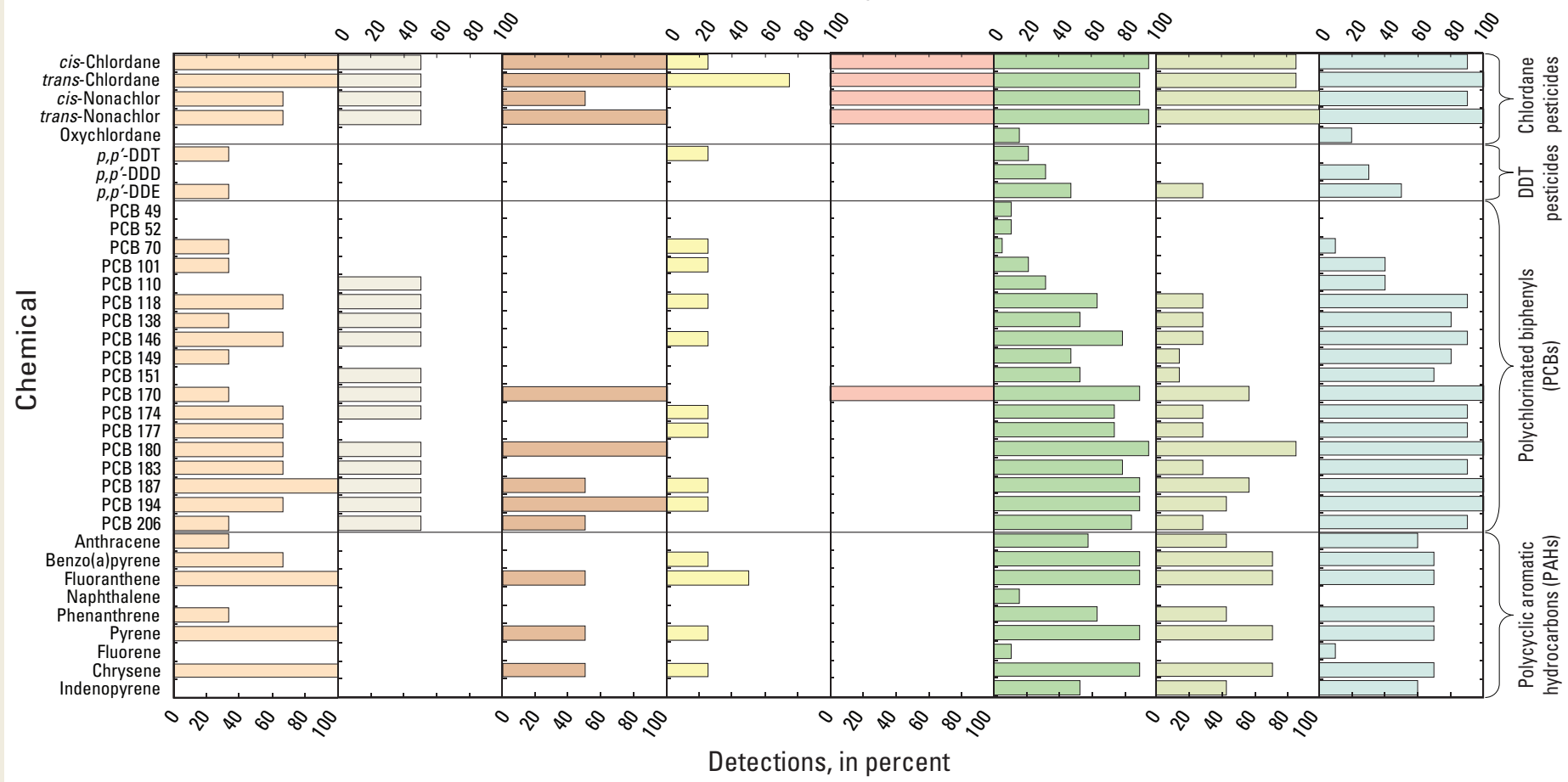

Figure 2. Detection frequencies of pesticides, polychlorinated biphenyls, and polycyclic aromatic hydrocarbons in streambed- and suspended-sediment samples, by watershed, in Bexar County, Texas, 2007-09.

Table 1. The sediment-quality guidelines of MacDonald and others (2000) were used to to evaluate the potential toxicity of contaminants to organisms living in the sediment.

$[\mu \mathrm{g} / \mathrm{g}$, micrograms per gram; $\mu \mathrm{g} / \mathrm{kg}$, micrograms per kilogram; DDE, dichlorodiphenyldichloroethylene; PCB, polychlorinated biphenyls; PAH, polycyclic aromatic hydrocarbons]

- TEC, threshold effect concentration; concentrations below the TEC should not have a harmful effect on organisms living in the sediment.

- PEC, probable effect concentration; concentrations above the PEC are likely to have a harmful effect on organisms living in the sediment.

- Samples with concentrations between the TEC and PEC are predicted to be neither toxic nor nontoxic.

\begin{tabular}{lcc}
\hline \multicolumn{1}{c}{ Chemical } & TEC & PEC \\
\hline Cadmium $(\mu \mathrm{g} / \mathrm{g})$ & 0.99 & 4.98 \\
Chromium $(\mu \mathrm{g} / \mathrm{g})$ & 43.4 & 111 \\
Lead $(\mu \mathrm{g} / \mathrm{g})$ & 35.8 & 128 \\
Zinc $(\mu \mathrm{g} / \mathrm{g})$ & 121 & 459 \\
Chlordane $(\mu \mathrm{g} / \mathrm{kg})$ & 3.24 & 17.6 \\
DDE $(\mu \mathrm{g} / \mathrm{kg})$ & 3.16 & 31.3 \\
Total PCB $(\mu \mathrm{g} / \mathrm{kg})$ & 59.8 & 676 \\
Total PAH $(\mu \mathrm{g} / \mathrm{kg})$ & 1,610 & 22,800 \\
\hline
\end{tabular}

- PCBs were found in 90 percent of the samples; they were found in every watershed and most often in the samples collected from Leon Creek and San Antonio River.

- PAHs were found in 75 percent of the samples; no PAHs were found in the samples collected from Medina River or Chupaderas Creek. PAHs were found most often in the samples collected from Leon Creek and San Antonio River.

\section{Sediment-Quality Guidelines-Are These Concentrations High?}

The concentrations of chemicals in sediments can be compared to sediment-quality guidelines (table 1, fig. 3 ) to evaluate the potential toxicity of contaminants to organisms living in the sediment. The sediment-quality guidelines used in this fact sheet (MacDonald and others, 2000) are not regulatory limits and do not necessarily mean harmful effects are expected on humans or other animals exposed to the sediments. 

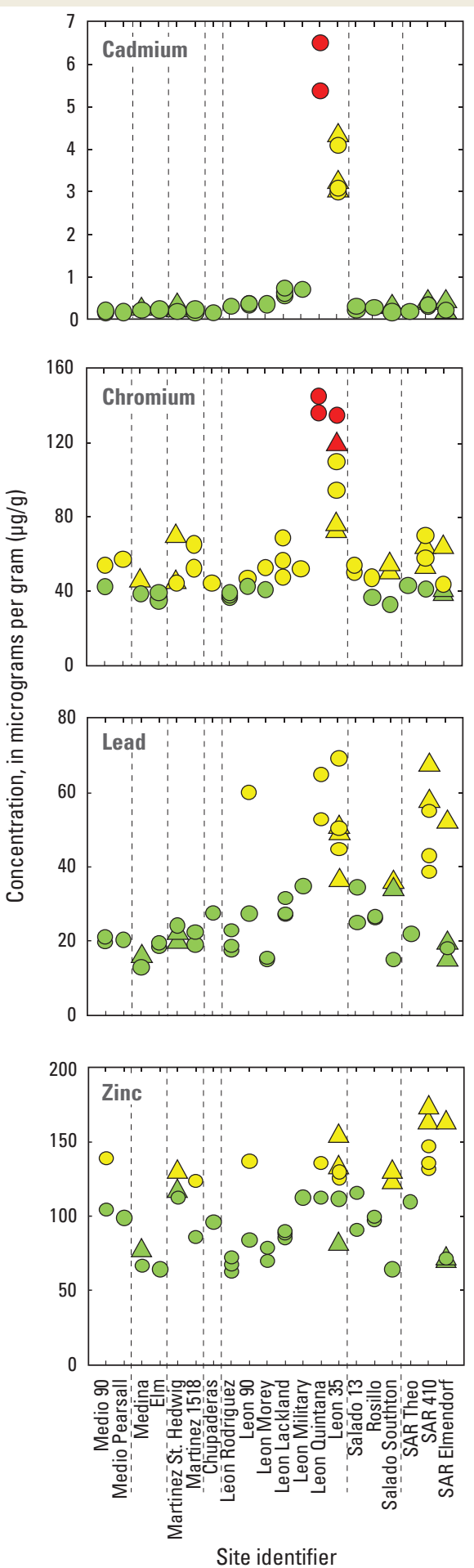

Site identifier
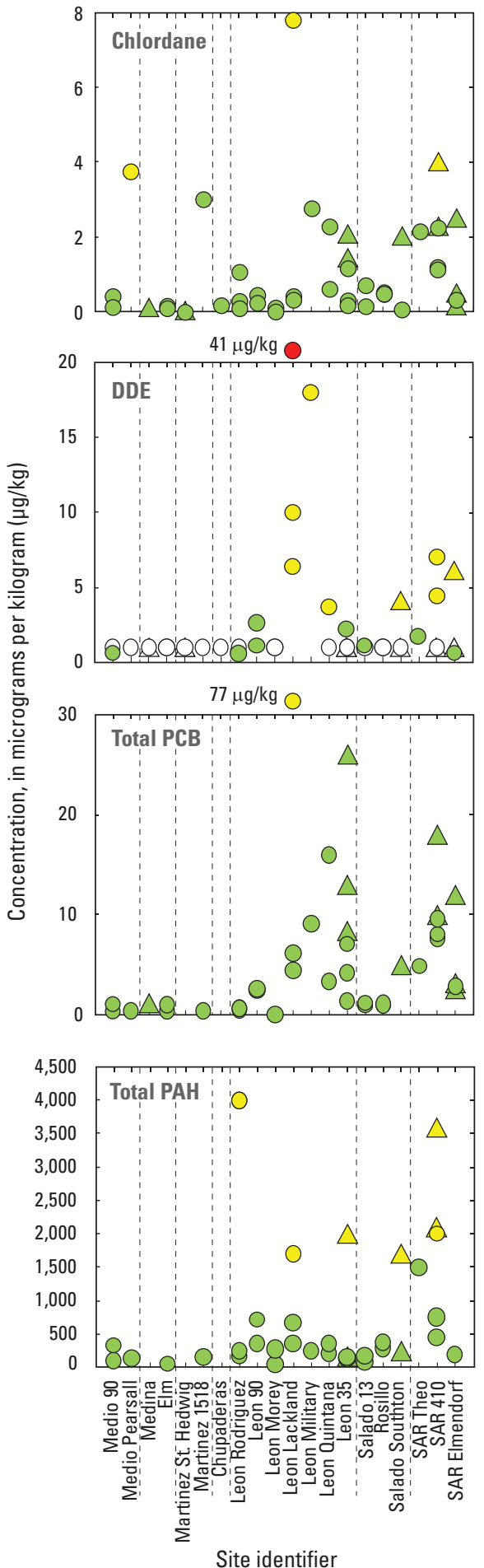

EXPLANATION

Streambed-sediment sample concentration

Concentration more than probable effect concentration (PEC)

Concentration more than threshold effect concentration (TEC)

Concentration less than threshold effect concentration (TEC)

$\bigcirc$ Nondetection at interim reporting level; not shown for total PCB or total PAH
Suspended-sediment sample concentration

$\triangle$ Concentration more than probable effect concentration (PEC)

$\triangle$ Concentration more than threshold effect concentration (TEC)

$\triangle$ Concentration less than threshold effect concentration (TEC) not shown for total PCB or total PAH

SAR San Antonio River $\triangle$ Nondetection at interim reporting level;

Figure 3. Comparison of sediment-quality guildelines to concentrations in streambedsediment (circles) and suspended-sediment (triangles) samples collected from sites in Bexar County, Texas, 2007-09.

- Cadmium concentrations were greater than the probable effect concentration (PEC) in two samples collected from the Leon Quintana site; six samples collected from the Leon 35 site had concentrations greater than the threshold effect concentration (TEC).

- Chromium concentrations were greater than the PEC in two samples collected from the Leon Quintana site and in two samples collected from the Leon 35 site; 69 percent of all samples had concentrations greater than the TEC.

- Lead concentrations were greater than the TEC in 33 percent of all samples, no samples had concentrations greater than the PEC.

- Zinc concentrations were greater than the TEC in 35 percent of all samples, no samples had concentrations greater than the PEC.

- Chlordane concentrations were greater than the TEC in one sample collected from each of the following sites: Medio Pearsall, Leon Lackland, and SAR 410.

- DDE concentration was greater than the PEC in one sample collected from the Leon Lackland site; 19 percent of all samples had concentrations greater than the TEC.

- Total PCB concentration was greater than the TEC in one sample collected from the Leon Lackland site.

- Total PAH concentrations were greater than the TEC in 15 percent of all samples.

\section{References Cited}

MacDonald, D.D., Ingersoll, C.G., and Berger, T.A., 2000, Development and evaluation of consensusbased sediment quality guidelines for freshwater ecosystems: Archives of Environmental Contamination and Toxicology, v. 39, p. 20-31.

U.S. Census Bureau, 2009, Table 1-Annual estimates of the resident population for incorporated places over 100,000 , ranked by July 1, 2008 population (April 1, 2000 to July 1, 2008): U.S. Census Bureau, Population Division, p. 1.

\section{This fact sheet is based on the following report:}

Wilson, J.T., 2011, Assessment of selected contaminants in streambed- and suspendedsediment samples collected in Bexar County, Texas, 2007-09: U.S. Geological Survey Scientific Investigations Report 2011-5097, 57 p.

- Jennifer T. Wilson

For additional information, contact

Director, USGS Texas Water Science Center http://tx.usgs.gov/

gs-w-txpublic-info@usgs.gov 